\title{
AN EXAMINATION OF MEDICAL IMAGING LITERATURE IN MALAYSIAN CITATION INDEX (MyCite)
}

\author{
Nurul Husna Kamarudin ${ }^{1}$, Nor Azlina Ab Rahman ${ }^{2}$ and Zainul Ibrahim Zainuddin ${ }^{1}$ \\ ${ }^{1}$ Department of Diagnostic Imaging and Radiotherapy, Kulliyyah of Allied Health \\ Sciences, International Islamic University Malaysia, ${ }^{2}$ Department of Physical \\ Rehabilitation Sciences, Kulliyyah of Allied Health Sciences, International Islamic \\ University Malaysia.
}

Presenter: Nurul Husna Kamarudin, husnataqwa@gmail.com

Introduction: The Medical imaging service in Malaysia is expanding. The presence of imaging technologies needs to be supported by homegrown research to optimize their use. This study investigated the contribution of researches by Malaysian practitioners to the field of Medical imaging in the Malaysian Citation index (MyCite) database.

Materials and method: Bibliometric and thematic analyses were performed on publications featured in the database from 2006 to 2016 using 13 keywords; radiology, radiography, medical imaging, radiation, $x$-ray, neuroimaging, nuclear imaging, magnetic resonance imaging, computed tomography scan, mammogram, ultrasound, fluoroscopy, and intravenous urogram.

Results: A total of 268 articles were identified. The study reported the publications from Malaysians $(54.1 \%)$ followed by non-Malaysians $(41.8 \%)$ and collaboration between authors $(4.1 \%)$. The researchers were mostly from university-based $(67.4 \%)$ and hospital university-based $(21.3 \%)$ compared to clinical-based $(5.6 \%)$ researchers. For thematic analysis, the majority of the authors focused on certain topics such as clinical (42.9\%) and modality $(20.1 \%)$ with only a few on safety $(12.3 \%)$, technical $(9.7 \%)$, education (7.46\%), professionalism (4.5\%), quality $(2.6 \%)$ and economy $(0.4 \%)$ researches.

Conclusion: The low number of publications related to Medical imaging do not reflect the real involvement of practitioners in research. Their research findings could have been indexed in other databases besides MyCite. However, the open access facility offered by MyCite should be optimized. The involvement of clinical-based practitioners can be enhanced in areas involving safety, technical, education, professionalism, quality and economy. Collaborative efforts by the practitioners could increase the number of publications and enhance homegrown research that will address local needs. 